\title{
Purification of a Sinapine-Glucoraphanin Salt from Broccoli Seeds
}

\author{
Mark A. Berhow ${ }^{1 *}$, Karl Vermillion ${ }^{1}$, Gulab N. Jham², Brent Tisserat ${ }^{1}$, Steven F. Vaughn ${ }^{1}$ \\ ${ }^{1}$ United States Department of Agriculture, Agricultural Research Service, National Center for Agricultural Utilization Research, \\ Functional Foods Research, Peoria, USA; ${ }^{2}$ Universidade Federal de Viçosa, Departamento de Fitopatologia, Viçosa, Brazil. \\ Email: *mark.berhow@ars.usda.gov
}

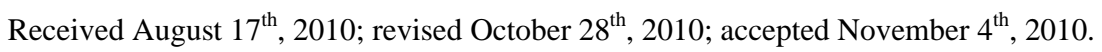

\begin{abstract}
A sinapine (sinapoylcholine)-glucoraphanin salt has been isolated from broccoli seeds and characterized by NMR and mass spectrometry. This salt extraction method can be used to purify glucoraphanin free from contamination by glucoiberin.
\end{abstract}

Keywords: Broccoli, Brassica, Glucoraphanin, Sinapine, Glucosinolate, Salt

\section{Introduction}

Broccoli seeds contain several glucosinolates, including glucoraphanin, glucoiberin, glucoerucin, sinigrin, 4-hydroxyglucobrassicin, glucobrassicin, neoglucobrassicin, and a number of other minor glucosinolates depending on the hybrid and cultivar [1,2]. Glucoraphanin has attracted attention due to studies linking its degradation products, including its isothiocyanate form sulphoraphane, to the prevention of cancer in humans $[3,4]$. Due to the complex mixture of the glucosinolates in the Brassica species, isolation of large quantities of pure glucosenolates for further study and biological characterization has been difficult, time consuming, and expensive [5-7].

Brassica species also contain significant quantities of substituted phenolic acids, including sinapine [8-13]. These phenolic acids have been shown to have antioxidant activity $[14,15]$ and may also play a role in the health promoting activities of a diet high in crucifer vegetables. Two major UV absorbing compounds were isolated from broccoli seeds, which decreased during the course of germination and sprouting. Characterization of these compounds resulted in the identification of a unique salt formed from the combination of sinapine and glucoraphanin, while the second compound was shown to be the methyl ester of sinapic acid.

\footnotetext{
*Mention of trade names or commercial products in this publication is solely for the purpose of providing specific information and does not imply recommendation or endorsement by the U.S. Department of Agriculture. USDA is an equal opportunity provider and employer.
}

\section{Results}

$\mathrm{MeOH}$ extracts prepared from broccoli seeds were separated and characterized with a general phenolic HPLC gradient system monitored at $285 \mathrm{~nm}$ for phenolic compounds. The resulting chromatograph showed two major peaks at $285 \mathrm{~nm}$ with retention times of 10 and 33 minutes. The two compounds (compounds 1 and 2) were purified from the $\mathrm{MeOH}$ extract using a combination of flash chromatography and preparative HPLC, yielding $115 \mathrm{mg}$ of compound 1 and $133 \mathrm{mg}$ of compound 2 from $1 \mathrm{~kg}$ of defatted broccoli seeds.

\subsection{Spectral Analysis}

Compound 1 appeared pure by HPLC DAD, and the ${ }^{1} \mathrm{H}$ and ${ }^{13} \mathrm{C}$ NMR spectra were obtained from five milligrams (Table 1). Initial NMR spectra showed that there were two components present in the purified compound 1 (in addition to acetate) that were not fixed in their stoichiometry. Different batches of the product always contained both components, but in slightly varying ratios.

The more abundant compound contained two coupled olefinic protons at $7.70 \mathrm{ppm}(1 \mathrm{H}, \mathrm{d}, J=15.9 \mathrm{~Hz}, \mathrm{H}-7)$ and $6.47 \mathrm{ppm}(1 \mathrm{H}, \mathrm{d}, \mathrm{H}-8)$ and an aromatic singlet at 6.96 ppm (2H, s, H-2/6), which suggested a symmetrically substituted ring system with an olefinic side chain. The geometry of the olefinic double bond was determined to be trans on the basis of the coupling constants. The NMR spectrum was consistent with a 2,4,6- or a 3,4,5-trioxy-substituted cinnamic acid fragments, including the carboxylic carbon at 166.4 ppm (C-9). Two 
methoxy-resonances at $3.90 \mathrm{ppm}(6 \mathrm{H}, \mathrm{s}, \mathrm{H}-3 / 5-\mathrm{OMe})$ showed correlations to the aromatic ring carbon at 148.1 ppm (C-3/5) in the HMBC NMR spectrum. Since the substitution pattern must be symmetric, the methoxy-substituents must be at the 3 and 5 positions, or alternately at the 2 and 6 positions, leaving position 4 as a phenolic moiety. Simulations conducted with ACDLabs CNMR predictor quickly eliminated the 2,4,6- substitution pattern and confirmed the 3,4,5- substitution pattern. Other signals included in this more abundant fragment included two strongly coupled methylene protons 4.68 ppm $(2 \mathrm{H}, \mathrm{m}, \mathrm{H}-10)$ and $3.79 \mathrm{ppm}(2 \mathrm{H}, \mathrm{m}, \mathrm{H}-11)$. The protons at $4.68 \mathrm{ppm}(\mathrm{H}-10)$ showed a weak correlation in the HMBC NMR spectrum to the carboxylic carbon C-9 while the protons at $3.79 \mathrm{ppm}(\mathrm{H}-11)$ showed a 1:1:1 splitting pattern, characteristic of coupling to a spin 1 quadrupolar nucleus such as nitrogen. This implied that the methylene at $4.68 \mathrm{ppm}$ would have an ester linkage to the rest of the fragment, while there was probably a nitrogen atom attached to the methylene at $3.79 \mathrm{ppm}$. In addition, the singlet at $3.27 \mathrm{ppm}(9 \mathrm{H}, \mathrm{s}, \mathrm{N}-\mathrm{Me})$ showed a correlation to the methylene carbon C-11 attached to the nitrogen atom in the HMBC NMR spectrum. This suggested a quaternary ammonium salt with three methyl substituents. The remaining position on the quaternary nitrogen was the $-\mathrm{CH}_{2}-\mathrm{CH}_{2}$ - branch linked by an ester to the substituted cinnamic acid fragment. This compound was identified as sinapine. The NMR data for this compound compared well with those shown for (E)-sinapoylcholine 4-O-ß-glucopyranoside [16].

The minor component contained a hexose sugar. Inspection of the HSQC NMR spectrum indicated shifts typical of an anomeric proton $4.85 \mathrm{ppm}\left(1 \mathrm{H}, \mathrm{H}-1^{\prime}\right)$, but in the ${ }^{13} \mathrm{C}$ dimension of the HSQC spectrum the C-1' carbon (82.2 ppm) did not have a shift typical of an anomeric carbon (normally 95-104 ppm). This suggested this fragment was not an $O$-glycoside and had some other linkage to the rest of the molecule. Overlap in the COSY NMR spectra made interpretation difficult, but the HSQC NMR spectrum showed the presence of a 4-carbon methylene chain (C-1,2,3,4), and an isolated methyl group (C-5). The carbon atom (C-4) at one end of this chain had a shift of $53.0 \mathrm{ppm}$, which is somewhat upfield for an oxygen-bearing carbon. It is more characteristic of a nitrogen- or sulfur-containing moiety attached to the carbon. Several simulations with ACDLab software suggested a sulfoxide would account for the ${ }^{13} \mathrm{C}$ NMR shifts for the methylene at C-4 and the isolated methyl at C-5. The protons at $2.75 \mathrm{ppm}(2 \mathrm{H}, \mathrm{m}, \mathrm{H}-1)$ on the other end of this chain showed a weak correlation in the HMBC NMR spectrum to the carbon at $159.4 \mathrm{ppm}$ (the oddly-named C-0 of glucosinolate nomenclature). This carbon at 159.4 ppm showed another HMBC NMR correlation from the “anomeric” proton $\mathrm{H}-1$ ' of the sugar fragment. The NMR analysis, along with the mass spectrometry data, which supported the presence of a sulfate group, indicated this compound was glucoraphanin [16].

Full spectral assignments of the observed ${ }^{1} \mathrm{H}$ and ${ }^{13} \mathrm{C}$ NMR shifts indicated that purified compound 1 was a mixture of sinapine and glucoraphanin (Figure 1) .

Table 1. NMR spectroscopic data $\left(\mathrm{CD}_{3} \mathrm{OD},{ }^{1} \mathrm{H} 500 \mathrm{MHz}\right.$, ${ }^{13} \mathrm{C} 125 \mathrm{MHz}$ ) for compound 1.

\begin{tabular}{|c|c|c|c|}
\hline \multirow[b]{2}{*}{ Carbon \# } & \multicolumn{3}{|c|}{ NMR Spectroscopic data } \\
\hline & $\begin{array}{l}{ }^{1} H \text { Shift } \\
\text { (ppm) }\end{array}$ & $\begin{array}{l}{ }^{1} \mathrm{H} \text { Splitting, } \\
\text { coupling }(\mathrm{Hz})\end{array}$ & $\begin{array}{l}{ }^{13} \text { C Shift } \\
\text { (ppm) }\end{array}$ \\
\hline \multicolumn{4}{|l|}{ Sinapine } \\
\hline 1 & - & & 125.0 \\
\hline 2 & 6.96 & s & 105.8 \\
\hline 3 & - & & 148.1 \\
\hline 4 & - & & 138.7 \\
\hline 5 & - & & 148.1 \\
\hline 6 & 6.96 & $\mathrm{~s}$ & 105.8 \\
\hline 7 & 7.70 & d, 15.9 & 146.9 \\
\hline 8 & 6.47 & d, 15.9 & 113.3 \\
\hline 9 & - & & 166.4 \\
\hline 10 & 4.68 & $\mathrm{~m}$ & 57.4 \\
\hline 11 & 3.79 & $\mathrm{~m}$ & 64.9 \\
\hline 3,5-OMe & 3.90 & $\mathrm{~s}$ & 55.5 \\
\hline $\mathrm{N}-\mathrm{Me}$ & 3.27 & s & 53.1 \\
\hline \multicolumn{4}{|c|}{ Glucoraphanin } \\
\hline 0 & - & & 159.4 \\
\hline 1 & 2.75 & $\mathrm{~m}$ & 31.6 \\
\hline 2 & 1.92 & * & 25.5 \\
\hline 3 & 1.87 & $\mathrm{~m}$ & 21.5 \\
\hline 4 & $2.82,2.91$ & $\mathrm{~m} ; \mathrm{m}$ & 53.0 \\
\hline 5 & 2.64 & $\mathrm{~s}$ & 36.6 \\
\hline $1^{\prime}$ & 4.85 & $*$ & 82.2 \\
\hline $2^{\prime}$ & 3.26 & $*$ & 72.8 \\
\hline 3 , & 3.41 & $\mathrm{t}, 8.8$ & 78.2 \\
\hline 4 ' & 3.29 & * & 69.9 \\
\hline 5 ' & 3.36 & $\mathrm{~m}$ & 81.0 \\
\hline 6’a,b & $3.62,3.86$ & dd, 6.3, 12.0; m & 61.4 \\
\hline acetate & 1.93 & s & $21.8 ; 177.4$ \\
\hline
\end{tabular}

*Multiplicity not determined due to spectral overlap with acetate and solvent peaks. ${ }^{* *}$ Chemical shifts $(\delta)$ are in ppm from TMS.

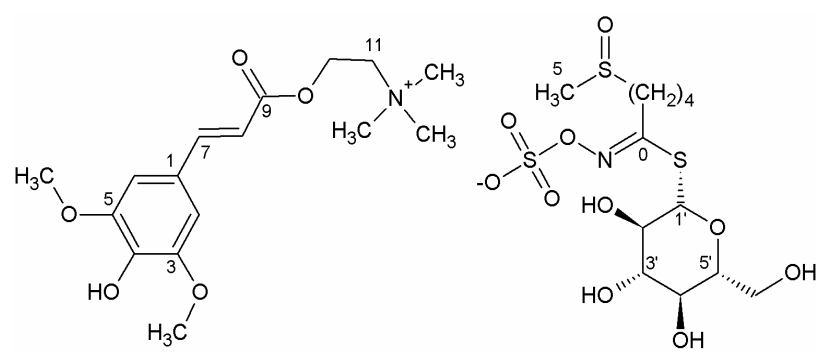

Figure 1. Structure of compound 1: a sinapine-glucoraphanin salt, for glucosinolate numbering system see [16]. 
The salt was contaminated with a small amount of acetate, likely due to the purification method, which contained acetic acid. This was probably acquired during the freeze-drying step to obtain the purified salt. The complete NMR spectra obtained for compound 1 agreed very closely with that published for a similar compound, Boreavan A purified and characterized from Boreava orientalis, which is a sinapine and sinigrin salt $[17,18]$. The NMR assignment for the sinapine fragment agreed closely with the similar (E)-sinapoylcholine 4-O-ß-glucopyranoside [19] and the NMR assignment for the glucoraphanin fragment agreed closely with the published spectra of the ammonium salt of glucoraphanin [16].

Compound 1 was infused under the conditions described in the materials and methods section into an ESI mass spectrometer in both the positive and negative modes. The positive ESI mass spectrum yielded a single major ion at $m / z$ 310, which corresponds to the $[\mathrm{M}]^{+}$ion of sinapine. In the presence of formic acid, the spectrum showed $\mathrm{m} / \mathrm{z}$ ions at 354,663 , and 973 , corresponding to $[\mathrm{M}]^{+},[2 \mathrm{M}]^{+}$and $[3 \mathrm{M}]^{+}$adducts with formic acid, respectively. The negative ESI mass spectrum yielded two major ions at $\mathrm{m} / \mathrm{z} 436$ and 873 , with a minor ion at $\mathrm{m} / \mathrm{z} 895$. These correspond to $\left[\mathrm{M}^{-},[2 \mathrm{M}+\mathrm{H}]^{-}\right.$, and the $[2 \mathrm{M}+\mathrm{Na}]^{-}$ ions of glucoraphanin. Electrospray mass spectrometry acquired in the negative mode of pure glucoraphanin resulting in similar spectra. From this data it was apparent that compound 1 was the salt of sinapine and glucoraphanin, contaminated with a small amount of acetate.

After assignment of the sinapine fragment of compound 1 it was obvious that compound 2 was a derivative of sinapic acid. Compound 2 was identified by NMR spectroscopy (Table 2) and mass spectrometry and found to be the methyl ester of sinapic acid (Figure 2). The ${ }^{1} \mathrm{H}$ and ${ }^{13} \mathrm{C}$ NMR spectrum compared closely with the published spectra of methyl-sinapate [20].

The spectral analysis of the sinapoylcholine-glucoraphanin salt was as follows-Isolated as light yellow crystals; mp $184-187^{\circ} \mathrm{C}$; UV (MeOH) $\lambda_{\max }$ (log e), 322 (3.60) $\mathrm{nm}$; IR (KBr, disc) $\lambda_{\max }\left(v \mathrm{~cm}^{-1}\right): 3036,3010$, 2940, 2845, 1706, 1632, 1595, 1515, 1457, 1427, 1338, 1279 (sh), 1254, 1232 (sh), 1153, 1114, 1055; LREIMS positive mode $\mathrm{m} / \mathrm{z} 310.2[\mathrm{M}]^{+}$and negative mode $\mathrm{m} / \mathrm{z}$ 436.4 [M]'; HREIMS positive mode $\mathrm{m} / \mathrm{z} 310.1657$ [M] $^{+}$ (calcd. for $\mathrm{C}_{16} \mathrm{H}_{24} \mathrm{NO}_{5}, 310.1654$ ); negative mode $\mathrm{m} / \mathrm{z}$ $436.0424 \mathrm{M}^{-}$(calcd. for $\mathrm{C}_{12} \mathrm{H}_{22} \mathrm{NO}_{10} \mathrm{~S}_{3}$, 436.0406). For ${ }^{1} \mathrm{H}$ and ${ }^{13} \mathrm{C}$ NMR spectroscopic data, see Table 1.

\section{Discussion}

Glucosinolates have previously been shown to be converted enzymatically or chemically to a number of degradation products, such as isothiocyanates, nitriles, and thiocyanates, once the plant tissue that they are contained in is damaged or consumed [21]. These degradation products have been shown to have a wide array of biological activities both in vivo and in vitro [1,3,4]. The isothiocyanate degradation product of glucoraphanin is sulforaphane which has been shown in extensive studies to have a number of interesting cancer chemo-preventive activities in both in vivo and in vitro studies [3,4]. Broccoli and related species have fairly high levels of glucoraphanin in their seeds and sprouts and are excellent sources of these compounds for purification and study. While conversion of glucoraphanin to sulforaphane is fairly simple, the purification of glucoraphanin is complicated by the presence of other glucosinolates in the seeds especially glucoiberin, which co-elutes in most chromatographic procedures.

A recently published method using counter current chromatography resulted in the purification of 61 grams of glucoraphanin from 500 grams of crude broccoli seed extract [22]. The authors did not state how many grams of broccoli seed were used to obtain the 500 grams of extract. The chromatographic isolation of the sinapine glucoraphanin salt is more straight-forward and provides

Table 2. NMR spectroscopic data (CD3OD, 1H $500 \mathrm{MHz}$ 13C $125 \mathrm{MHz}$ ) for compound 2.

\begin{tabular}{cccc}
\hline & \multicolumn{3}{c}{ NMR Spectroscopic data } \\
\cline { 2 - 4 } Carbon \# & $\begin{array}{c}{ }^{1} \text { H Shift } \\
(\text { ppm })\end{array}$ & $\begin{array}{c}{ }^{1} \text { H Splitting, } \\
\text { coupling }(\mathrm{Hz})\end{array}$ & $\begin{array}{c}{ }^{13} \text { C Shift } \\
(p p m)\end{array}$ \\
\hline 1 & - & & 125.2 \\
2 & 6.91 & s & 105.6 \\
3 & - & & 148.1 \\
4 & - & & 138.3 \\
5 & - & s & 148.1 \\
6 & 6.91 & d, 15.9 & 105.6 \\
7 & 7.62 & d, 15.9 & 145.6 \\
8 & 6.40 & & 114.3 \\
9 & - & s & 168.2 \\
10 & 3.78 & s & 50.6 \\
$3,5-O M e$ & 3.89 & & 55.5 \\
\hline
\end{tabular}

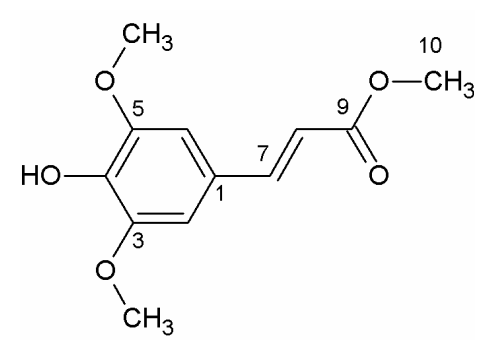

Figure 2. Structure of compound 2: sinapic acid methyl ester. 
a good separation even with very crude chromatographic methods such as flash chromatography. The purified salt is free from contamination by glucoiberin. The purified sinapine-glucoraphanin salt can be passed through an anion exchange column to remove the sinapine and eluted with potassium sulfate if the potassium salt is needed. Further development and refinement of this purification technique promises to increase the yields and may provide an alternative method for the production of pure glucoraphanin than the conventional chromatographic isolation of the acid, or for the sodium or potassium salts. Sinapine also has biological activity [13-15], and the two compounds together may have interesting biological activities as an enhanced antioxidant and for the prevention of chronic diseases.

\section{Experimental}

\subsection{Chemicals}

All chemicals were of analytical reagent grade and purchased from national distribution venders. Solvents for chromatography were purchased from EMD-Merck (Gibbstown, New Jersey, USA). Water was purified using a ELGA Pure Lab Ultra system from Veolia Water Solutions and Technologies (Woodbridge, Illinois, USA).

\subsection{Sample Preparation and Extraction}

Broccoli seeds (Brassica oleracea L. var. botrytis cv. 'Liberty') were obtained from Sakata Seed America (Morgan Hill, CA). One kg of seeds were ground to a fine powder in a commercial coffee grinder and defatted overnight in four Soxhlet extractors (250 g each) with hexane for 24 hours. The hexane was then removed and the samples were dried in a fumehood for 24 hours. The defatted samples were then extracted in four Soxhlet extractors with $\mathrm{MeOH}$ for 72 hours. The pooled $\mathrm{MeOH}$ extracts from the original $1 \mathrm{~kg}$ of ground seed samples was evaporated to dryness in a rotary evaporator and resuspended in approximately $100 \mathrm{~mL}$ 50:50 MeOH: $\mathrm{H}_{2} \mathrm{O}$.

\subsection{Isolation and Purification}

A Büchi (Newcastle, DE) Sepacore flash chromatography system with dual C-605 pump modules, C-615 pump manager, C-660 fraction collector, C-635 UV photometer, with SepacoreRecord chromatography software was used. A Büchi C-670 Cartridger system to load $40 \times 150 \mathrm{~mm}$ flash columns with approximately 90 grams of preparative C-18 reverse-phase bulk packing material (125 $\AA$, 55-105 $\mu$, Waters Corp, Milford, MA). The columns were installed in the flash chromatography system and equilibrated with $20 \% \mathrm{MeOH}$ and $0.5 \% \mathrm{HOAc}$ in water for five minutes at a flow rate of $30 \mathrm{~mL}$ per minute. After samples $(20 \mathrm{~mL})$ were injected, the column was developed with a binary gradient to $50 \% \mathrm{MeOH}$ over 30 minutes. The eluant was monitored at $237 \mathrm{~nm}$ and fractions based on absorbance were collected in the fraction collector by the software program. This was repeated 5 times to purify the entire extracted sample. Three major broad UV-absorbing peaks (fractions A, B, and C) were collected. The fractions were evaluated by analytical HPLC. Fraction A contained a single major UV absorbing peak with a retention time of 10 minutes (compound 1), and fraction $\mathrm{C}$ contained a single major UV absorbing peak at 33 minutes (compound 2). Fraction B contained a mixture of several peaks including those found in Fraction $\mathrm{A}$ and $\mathrm{C}$. Fractions $\mathrm{A}$ and $\mathrm{C}$ were evaporated to dryness with nitrogen gas and resuspended in $30 \mathrm{~mL}$ of 1:1 mix of $\mathrm{MeOH}$ and water.

Fractions $\mathrm{A}$ and $\mathrm{C}$ were further purified using a Shimadzu (Columbia, MD) preparative HPLC system was used with dual 8A pumps, SIL 10vp autoinjector, SPD M10Avp photodiode array detector, SCL 10Avp system controller all operating under the Shimadzu Class VP operating system. Ten mL sample aliquots in 1:1 MeOH: water were injected on a Phenomenex (Torrance, CA) Luna C-18(2) semi-preparative reversed-phase column $(10 \mu, 100 \AA, 250 \times 50 \mathrm{~mm})$. The column was preequilibrated with a solvent system consisting of $10 \%$ $\mathrm{MeOH}$ and $90 \%$ water (containing 1\% HOAc) at a flow rate of $50 \mathrm{~mL}$ per minute and the eluant was monitored at $237 \mathrm{~nm}$. The column was developed to $100 \% \mathrm{MeOH}$ over 50 minutes. The major UV absorbing peak in each fraction was collected, pooled, allowed to evaporate for removal of the $\mathrm{MeOH}$, then freeze-dried to remove the remaining water to afford approximately $115 \mathrm{mg}$ of pure compound 1 and 133 mg of pure compound 2 .

\subsection{HPLC Analysis}

General phenolic HPLC analysis was conducted on a Shimadzu LC-20 HPLC system (LC-20AT quaternary pump, DGU-20A5 degasser, SIL-20A HT autosampler, and a SPD M20A photodiode array detector, running under Shimadzu LCSolution version 1.22 chromatography software, Columbia, MD, USA). The column used was an Inertsil ODS-3 reversed-phase C-18 column (5 $\mu$, $250 \times 4.6 \mathrm{~mm}$, with a Metaguard column, from Varian). The initial conditions were $20 \% \mathrm{MeOH}$ and $80 \% 0.01 \mathrm{M}$ $\mathrm{H}_{3} \mathrm{PO}_{4}$ in water, at a flow rate of $1 \mathrm{~mL}$ per minute. The eluant was monitored at $285 \mathrm{~nm}$ on the PDA. After injection (typically $15 \mu \mathrm{L}$ ), the column was held at the initial conditions for 2 minutes, then developed to $100 \% \mathrm{MeOH}$ in a linear gradient over 50 minutes.

For the glucosinolate analysis, a modification of a HPLC method developed by Betz and Fox was used [23] which gives excellent resolution of glucosinolates with- 
out peak tailing, due to good ion pairing from the solvent. The extract was run on a Shimadzu (Columbia, MD) HPLC System (two LC 20AD pumps; SIL 20A autoinjector; DGU 20As degasser; SPD-20A UV-VIS detector; and a CBM-20A communication BUS module) using the Shimadzu EZStart Version 7.3 software. The column was a C-18 Inertsil reversed-phase column $(250 \mathrm{~mm} \times 4.6$ $\mathrm{mm}$; RP C-18, ODS-3, $5 \mu$; with a Metaguard guard column; Varian, Torrance, CA). The glucosinolates were detected by monitoring at $237 \mathrm{~nm}$. The initial mobile phase conditions were $12 \% \mathrm{MeOH} / 88 \%$ aqueous 0.005 M tetrabutylammonium bisulfate (TBS) at a flow rate of $1 \mathrm{~mL} /$ minute. After injection of $15 \mu \mathrm{L}$ of sample, the binary gradient was developed to $70 \% \mathrm{MeOH} / 30 \%$ aqueous $0.005 \mathrm{M}$ TBS for 30 minute, and then to $50 \%$ $\mathrm{MeOH} / 50 \%$ aqueous $0.005 \mathrm{M}$ TBS over another 20 minutes.

\subsection{HPLC-MS Analysis}

To obtain the molecular weights of the compounds found in the seed extracts, aliquots were injected on a ion-trap LC-MS. Samples were run on a ThermoFinnigan LCQ DECA XP Plus LC-MS system with a Surveyor HPLC system (autoinjector, pump, degasser and PDA detector) and a nitrogen generator all running under the Xcaliber 1.3 software system. The MS was run with the ESI probe in either the positive or the negative mode. The column was a $3 \mathrm{~mm} \times 150 \mathrm{~mm}$ Inertsil reversed-phase C-18, ODS-3, $3 \mu$, column (Varian, Torrance, CA) with a Metaguard guard column. Solvent A was $0.25 \%$ HOAc in $\mathrm{H}_{2} \mathrm{O}$ and Solvent B was $0.25 \% \mathrm{HOAc}$ in $\mathrm{MeOH}$. The source inlet temperature was set at $250^{\circ} \mathrm{C}$, the sheath gas rate was set at 80 arbitrary units and the sweep (auxiliary) gas rate was set at 30 arbitrary units. The mass spectrometer was optimized for the detection of compounds in the extracts by using the autotune feature of the software while infusing a solution of the purified compounds in $\mathrm{MeOH}$ at a flow rate of $25 \mu \mathrm{L} /$ minute with the eluant of the column (50:50 solvent A and B) at a flow rate of $100 \mu \mathrm{L} /$ minute and tuning on the most prominent ion. Under these conditions the spray voltage was $4.0 \mathrm{kV}$ and the capillary voltage was $40 \mathrm{~V}$ (positive mode) and $-47 \mathrm{~V}$ (negative mode). An aliquot of the samples (typically 15 $\mu \mathrm{L}$ ) was then run on the LC. The initial HPLC conditions were $12 \% \mathrm{MeOH} / \mathrm{H}_{2} \mathrm{O}$ (containing $0.25 \% \mathrm{HOAc}$ ) at a flow rate of $0.3 \mathrm{~mL}$ per minute, then the column was developed to $34 \% \mathrm{MeOH} / \mathrm{H}_{2} \mathrm{O}$ (containing $0.25 \% \mathrm{HOAc}$ ) over 20 minutes and then to $50 \% \mathrm{MeOH} / \mathrm{H}_{2} \mathrm{O}$ (containing $0.25 \% \mathrm{HOAc}$ ) over an additional 20 minutes. The eluant was also monitored at 237 and $285 \mathrm{~nm}$ on the PDA.

\subsection{NMR Analysis}

${ }^{1} \mathrm{H}$, COSY, DEPT, and ${ }^{13} \mathrm{C}$ NMR spectra were obtained on a Bruker (Billerica, MA, USA) Avance 500 NMR spectrometer equipped with a $5 \mathrm{~mm}$ inverse broadband Z-gradient probe $\left({ }^{13} \mathrm{C}\right.$ NMR, $\left.125 \mathrm{MHz} ;{ }^{1} \mathrm{H}, 500 \mathrm{MHz}\right)$. NMR spectra were recorded in $\mathrm{CD}_{3} \mathrm{OD}$ and referenced to solvent resonances $\left({ }^{13} \mathrm{C}, 49.0 \mathrm{ppm},{ }^{1} \mathrm{H}, 3.30 \mathrm{ppm}\right)$. The data was analyzed using the Advanced Chemistry Development, Inc., SpecManager 1D Processor and the HNMR and CNMR Predictor software suite version 12.01 (Toronto, ONT.)

\section{Acknowledgements}

The authors would like to thank Ray Holloway and Sandra Duval for their technical assistance, Dr. Sherald $\mathrm{H}$. Gordon for providing the IR spectra, and Dr. Brian Moser for melting point determination.

\section{REFERENCES}

[1] J. W. Fahey, A. T. Zalcmann and P. Talalay, “The Chemical Diversity and Distribution of Glucosinolates and Isothiocyanates among Plants," Phytochemistry, Vol. 56, No. 1, 2001, pp. 5-51.

[2] M. W. Farnham, K. K. Stephenson and J. W. Fahey, "Glucoraphanin Level in Broccoli Seed is Largely Determined by Genotype,” HortScience, Vol. 40, No. 1, 2005, pp. 50-53.

[3] T. A. Shapiro, J. W. Fahey, K. L. Wade, K. K. Stephenson and P. Talalay, "Chemoprotective Glucosinolates and Isothiocyanates of Broccoli Sprouts: Metabolism and Excretion in Humans," Cancer Epidemiology, Biomarkers \& Prevention, Vol. 10, No. 5, 2001, pp. 501-508.

[4] P. Talalay and J. W. Fahey, "Phytochemicals from Cruciferous Plants Protect against Cancer by Modulating Carcinogen Metabolism,” Journal of Nutrition, Vol. 131, No. 11, 2001, pp. 3027-3033.

[5] J. W. Fahey, K. L. Wade, K. K. Stephenson and F. E. Chou, "Separation and Purification of Glucosinolates from Crude Plant Homogenates by High-Speed CounterCurrent Chromatography," Journal of Chromatography A, Vol. 996, No. 1-2, 2003, pp. 85-93.

[6] S. Rochfort, D. Caridi, M. Stinton, V. C. Trenerry and R. Jones, "The Isolation and Purification of Glucoraphanin from Broccoli Seeds by Solid Phase Extraction and Preparative High Performance Liquid Chromatography,” Journal of Chromatography A, Vol. 1120, 2006, pp. 205210.

[7] K. L. Wade, I. J. Garrard and J. W. Fahey, "Improved Hydrophilic Interaction Chromatography Method for the Identification and Quantification of Glucosinolates," Journal of Chromatography A, Vol. 1154, No. 1-2, 2007, pp. 469-472.

[8] T. Z. Felde, A. Baumert, D. Strack, H. C. Becker and C. Mollers, "Genetic Variation for Sinapate Ester Content in Winter Rapeseed (Brassica napus L.) and Development of 
NIRS Calibration Equations,” Plant Breeding, Vol. 126, No. 3, 2007, pp. 291-296.

[9] T. Z. Felde, H. C. Becker and C. Mollers, "Genotype, Environment Interactions, Heritability, and Trait Correlations of Sinapate Ester Content in Winter Rapeseed (Brassica napus L.)," Crop Science, Vol. 46, No. 5, 2006, pp. 2195-2199.

[10] R. J. Mailer, A. McFadden, J. Ayton and B. Redden, "Anti-Nutritional Components, Fibre, Sinapine and Glucosinolate Content, in Australian Canola (Brassica napus L.) Meal," Journal of the American Oil Chemists' Society, Vol. 85, No. 10, 2008, pp. 937-944.

[11] A. G. Taylor, D. B. Churchill, S. S. Lee, D. M. Bilsland and T. M. Cooper, "Color Sorting of Coated Brassica Seeds by Fluorescent Sinapine Leakage to Improve Germination," Journal of the American Society for Horticultural Science, Vol. 118, No. 4, 1993, pp. 551-556.

[12] A. G. Taylor, D. H. Paine and C. A. Paine, "Sinapine Leakage from Brassica Seeds," Journal of the American Society for Horticultural Science, Vol. 118, No. 4, 1993, pp. 546-550.

[13] C. Milkowski and D. Strack, "Sinapate Esters in Brassicaceous Plants: Biochemistry, Molecular Biology, Evolution and Metabolic Engineering," Planta, Vol. 232, No. 1, 2010, pp. 19-35.

[14] U. Thiyam, H. Stockmann, T. Z. Felde and K. Schwarz, "Antioxidative Effect of the Main Sinapic Acid Derivatives from Rapeseed and Mustard Oil By-Products," European Journal of Lipid Science and Technology, Vol. 108, No. 3, 2006, pp. 239-248.

[15] U. Thiyam, H. Stockmann and K. Schwarz, “Antioxidant Activity of Rapeseed Phenolics and Their Interactions with Tocopherols during Lipid Oxidation,” Journal of the American Oil Chemists' Society, Vol. 83, No. 6, 2006, pp. 523-528.
[16] T. Prestera, J. W. Fahey, W. D. Holtzclaw, C. Abeygunawardana, J. L. Kachinski and P. Talalay, "Comprehensive Chromatographic Separation and Spectroscopic Methods for the Separation and Identification of Intact Glucosinolates,” Analytical Biochemistry, Vol. 239, 1996, 168-179.

[17] A. Sakushima, M. Coskun and T. Maoka, "Sinapinyl But-3-Enylglucosinolate from Boreava orientalis," Phytochemistry, Vol. 40, No. 2, 1995, pp. 483-485.

[18] A. Sakushima, S. Ohnishi, H. Kubo and T. Maoka, "Study of Sinapinyl But-3-Enylglucosinolate (Boreavan A) and Related Compounds by Mass Spectrometry," Phytochemical Analysis, Vol. 8, No. 6, 1997, pp. 312-315.

[19] K. Wolfram, J. Schmidt, V. Wray, C. Milkowski, W. Schliemann and D. Strack, "Profiling of Phenylpropanoids in Transgenic Low-Sinapine Oilseed Rare (Brassica napus),” Phytochemistry, Vol. 71, 2010, 1076-1084.

[20] S. A. Ralph, J. Ralph and L. L. Landucci, "NMR Database of Lignin and Cell Wall Model Compounds,” 2004. http://ars.usda.gov/Services/ docs.htm?docid=10491

[21] S. F. Vaughn and M. A. Berhow, "Glucosinolate Hydrolysis Products from Various Plant Sources: pH Effects, Isolation, and Purification,” Industrial Crops and Products, Vol. 21, 2005, 193-204.

[22] Y. Fu, Q. Du and K. Wang, "Scale-Up of Slow Rotary Countercurrent Chromatographic Isolation of Glucoraphanin and Glucoraphenin from Broccoli Seeds and Radish Seeds,” Acta Chromatographica, Vol. 20, 2008, 697-707.

[23] J. M. Betz and W. D. Fox, "High-Performance Liquid Chromatographic Determination of Glucosinolates in Brassica Vegetables,” In: M.-T. Huang, T. Osawa, C.-T. Ho and A. T. Roen, Eds., Food Chemicals for Cancer Prevention I: Fruits and Vegetables, ACS Symposia series 546, ACS Publications, Washington, DC, 1994, pp 181-195. 